\title{
ESCENIFICACIONES EMOTIVAS EN UN CASO DE FOBIA INFANTIL EMOTIVE PERFORMANCES IN CHILDHOOD PHOBIA
}

\author{
Franciso Hurtado Perona*
}

Servicio de Psicología Aplicada. Universidad Nacional de Educación a Distancia (UNED)

\section{Resumen}

En este artículo presentamos un caso clínico de fobia a los ascensores en una niña de 4 años. El tratamiento, basado en la técnica de las escenificaciones emotivas, se mostró efectivo en sólo siete sesiones a lo largo de tres meses. Las ganancias terapéuticas se mantienen después de dos meses de seguimiento.

\section{Palabras clave}

Infancia, fobia específica, escenificaciones emotivas.

\begin{abstract}
In this paper, a case study of elevator phobia in a 4-year-old-girl is presented. A treatment based on the emotive performances technique showed to be effective in just seven sessions held in a three month period of time. The therapeutic outcome remains after a two-month follow-up.
\end{abstract}

Key words

Childhood, specific phobia, emotive performances.

\footnotetext{
* El autor desea agradecer a la profesora María Victoria del Barrio Gándara por sus comentarios y supervisiones en este caso.
} 


\section{Introducción}

La técnica de las escenificaciones emotivas desarrollada por Méndez y Maciá (1988), ofrece un contexto lúdico muy adecuado para el tratamiento de casos de fobia simple en niños pequeños, en la que se combinan el modelado simbólico y en vivo, la exposición gradual y el reforzamiento positivo, mediante el juego y la representación de papeles y argumentos reales e inventados.

El presente caso es de interés por la corta edad del sujeto (cuatro años), por el contexto familiar del que partió la demanda de ayuda, y por el tipo de intervención, que consistió fundamentalmente en una adaptación flexible y creativa de la técnica de las escenificaciones emotivas.

\section{Descripción del caso}

\section{Datos biográficos relevantes}

El sujeto, en adelante Ana, es una niña de 4 años, hija única, bien adaptada socialmente y rendimiento sobresaliente en el colegio. Fue diagnosticada de hemofilia durante el embarazo. Ambos padres son profesionales de nivel cultural alto, buenas habilidades educativas, y con antecedentes de solución exitosa de problemas sin ayuda externa (por ejemplo, las dificultades que tuvo Ana para aprender a dormir sola al dejar la cuna).

\section{Motivo de consulta e historia del problema}

Los padres de Ana acuden a consulta porque según sus palabras, ella sufre de fobia a los ascensores. Se niega a subir a cualquier ascensor, y se pone muy nerviosa si se le fuerza.

Cuentan que este problema empezó hace un mes y medio cuando se quedó encerrada en el ascensor del colegio junto con otros compañeros y la profesora. Algunas compañeras se pusieron a gritar y ella se asustó mucho.

\section{Contexto familiar}

Ambos padres estuvieron muy preocupados durante los dos primeros años de vida de la niña. Debido a su enfermedad cualquier lesión leve podía tener fatales consecuencias y tuvieron que guardar ciertas precauciones para evitar heridas y accidentes.

Actualmente, también decían tener preocupación por su impresión de haber sido demasiado protectores.

Como consecuencia, estaban muy alerta ante posibles indicios de "problemas psicológicos» en Ana. El padre tenía "prisa» porque su hija superara su "problema».

\section{Evaluación}

\section{Metodología}

La primera fuente de información consistió en una entrevista con ambos padres a la vez, mientras la niña estaba presente jugando «distraída». Además de obtener datos relevantes sobre el caso, nos permite presenciar in situ la dinámica familiar.

Los padres contestaron al cuestionario de síntomas infantiles Achenbach $\mathrm{Cbcl}$, que no mostró ninguna puntuación significativa salvo en lo tocante a algunos miedos relacionados con los ascensores.

Desde la primera sesión y a lo largo de todo el tratamiento, se diseñó un registro para ser cumplimentado por los padres, en el que se anotaba a diario la ocurrencia y detalles sobre la conducta problema en relación con los ascensores (ver figura 1).

Con la niña se utilizó una variación de las escenificaciones emotivas como técnica de evaluación, que consistía básicamente en proporcionarle muñecos para que ella libremente se inventara una historia y la escenificara. Una vez que la historia estaba en marcha, ella rápidamente solía involucrar al terapeuta para que la ayudara a representar papeles complementarios. Así, y sin necesidad de dirigir la representación, Ana expresaba sus dificultades y preocupaciones actuales a través de los personajes 


\begin{tabular}{|c|l|l|l|l|l|l|l|}
\hline Fecha & Sube/Baja & Se niega? & Pisos & Acompañantes & Lugar & Personas & Observaciones \\
\hline & & & & & & & \\
\hline \\
\hline
\end{tabular}

FIGURA 1

de sus historias, y no solo como una simple recreación de los hechos, sino que mediante la participación simultánea de varios personajes en la escena, todos con distintas actitudes y reacciones frente al suceso narrado, ella conseguía comunicar su propia experiencia en toda su riqueza y complejidad, sus actitudes y sus emociones con diversos matices y facetas. Por ejemplo, una de las primeras historias que ella voluntariamente escenificó fue la de unos niños en el ascensor de un colegio; el ascensor (representado por la tapa de una caja) es bastante inquieto y le gusta comer niños (representados por ositos de plástico de colores), así que cuando están todos dentro para ir a clase, aquel decide pararse y comérselos a todos. Entonces una niña (osito amarillo) se pone a gritar, y otra (osito verde) se asusta de los gritos, y una tercera (osito azul) increpa al ascensor para que los suelte a todos, mientras que hay un niño (osito rojo) que permanece tranquilo y dice en voz alta que no tiene miedo. Con esta historia no sólo nos está contando algo que ocurrió que la asustó, sino que también está dejando salir mediante todos los personajes a la vez, todas sus voces interiores que tuvieron o tienen algo que decir sobre los hechos. Esta fuente coral de información fue muy útil de cara al tratamiento pues nos mostraba simultáneamente las dificultades y los recursos personales para hacerlas frente de los que ya disponía Ana.

Por último, se entrevistó a Ana junto con sus padres para buscar otros recursos positivos, fundamentalmente los personajes favoritos de la niña que pudieran ayudar en las escenificaciones emotivas, y los posibles refuerzos con que motivar y premiar el cumplimiento del tratamiento. En cuanto a los personajes, de todos los candidatos a héroe nos quedamos con «los cinco fantásticos» porque le gustaban mucho a Ana y porque se prestaban muy bien para contar historias en las que el problema se resuelve mediante la aplicación de alguna habilidad especial (que por supuesto se puede aprender cuando el terapeuta revela su "secreto»). Cuando se investigaron los posibles refuerzos para motivar a Ana, quedó claro que no basta con preguntar, hay que ponerlos a prueba. No olvidemos que a un reforzador se le reconoce por sus efectos. Así, lo primero que sugirieron sus padres, monedas para la hucha, se mostró completamente inútil, y era incluso rechazado contundentemente ("¿Para qué me das esto, si no es mío?. No lo quiero.»). Quizás era previsible que con cuatro años todavía no hubiera interiorizado el valor simbólico (o si se prefiere, de reforzador secundario) del dinero. Sin embargo, la perspectiva de comerse un helado, que por los cuidados que su enfermedad había requerido llevaba años sin probar, resultó ser mucho más eficaz.

\section{Definición operativa del problema}

Después de organizar toda la información, se llegó a la siguiente definición consensuada del problema de Ana:

Cuando puede elegir, evita coger el ascensor el $50 \%$ de las veces, usando en su lugar las escaleras. Cuando no tiene más remedio que subir en ascensor (como por ejemplo en el colegio), manifiesta ansiedad (respiración agitada, sudor, se agarra fuerte de la mano de un adulto) y preocupación (pregunta constantemente si se va a parar, si va a pasar algo, etc., para conseguir seguridad). 


\section{Diagnóstico}

Si bien no se cumple el criterio temporal $\mathrm{F}$ de 6 meses de duración mínima de los síntomas exigido para menores de 18 años, y siguiendo la política del DSM-IV de otorgar gran importancia a la prevención y tratamiento precoces mediante la identificación de síndromes subclínicos, el diagnóstico con el que se procedió en este caso fue:

F40.2 Fobia específica [300.29] de tipo situacional (ascensores).

\section{Tratamiento}

Aunque se ha dividido el tratamiento en cuatro fases buscando una mayor claridad expositiva y organización de los datos, hay que decir que no reflejan necesariamente la secuencia temporal de los hechos, ni tampoco representan objetivos independientes entre sí, sino que más bien son intenciones terapéuticas muy solapadas e interrelacionadas tanto en la teoría como en la práctica. Como dicen Caballo y Simón (2002, p. 89): «El denominador común de las técnicas utilizadas, DS, inundación, práctica reforzada, aproximaciones sucesivas, modelado, es alguna forma de interaccionar con la estimulación fóbica. Un componente adicional es la reorganización de las contingencias, puesto que los padres de los niños con miedos desproporcionados y desadaptativos suelen sobreproteger a sus hijos.»

\section{Psicoeducación con los padres}

Primeramente nos centramos en normalizar la situación actual de los padres, es decir, en transmitirles una sensación de validez y legitimidad a sus preocupaciones apoyándonos en nuestro rol de experto, como paso previo para poder llegar a cuestionar su relación con el problema sin culpabilizarlos. Esto se consigue, por ejemplo, dando un sentido de normalidad a su preocupación con mensajes del tipo »tenéis razones de sobra para estar tan pendientes de vuestra hija», pero sobre todo, se comunica a través de la comprensión sincera de sus dificultades y la actitud de respeto por parte del terapeuta.
Muy relacionado con esto, también se abordó desde el principio la tarea de reforzar su estilo educativo y fortalecer su sentido de competencia como padres, buscando y señalando debidamente ejemplos en los que sus estrategias fueron eficaces, y reconociendo explícitamente el mérito de sus esfuerzos («a pesar de lo difícil de la situación, lo habéis hecho muy bien»).

Otro de los obstáculos al cambio que hubo que abordar explícitamente con los padres fue su preocupación secundaria (preocupación por haber estado demasiado preocupados, es decir, por haber protegido y vigilado excesivamente a la niña). El alivio de esta emoción secundaria (Greenberg y Pavio, 2000) se consiguió reformulando positivamente su preocupación primaria («hemos solucionado el problema tan fácilmente porque lo detectasteis muy pronto, y así hemos podido evitar mayores complicaciones»).

Como en todas las relaciones terapéuticas, antes de empezar a buscar soluciones hubo que reformular la demanda inicial («nuestra hija es muy miedosa») en términos que hicieran abordable el problema y que a la vez no cargaran negativamente la identidad de la interesada ( "queremos que nuestra hija vuelva a utilizar los ascensores»).

Una vez definida operativamente la meta de la terapia, entrenamos a los padres para que observaran y tomaran nota de la conducta objetivo mediante el registro mencionado en el apartado de evaluación.

También hubo que instruir a los padres en el manejo de contingencias, es decir, de las recompensas, los castigos, y sobre todo de la atención que dedicaban al problema. Por ejemplo, se les señaló que la costumbre de convertir cada negativa de Ana a subir en ascensor en una divertida carrera con su madre por las escaleras podía estar funcionando como un aliciente más, junto al miedo, para no cambiar sus costumbres. Se les explicó que la eficacia de un premio como reforzador se pierde completamente si se otorga antes de cumplirse la conducta objetivo, por ejemplo si dan un premio a cambio de una promesa de subir en el próximo ascensor, que era como venían aplicándolo hasta ahora. Otro cambio a este respecto consistió en enseñarles a no improvisar los premios sobre 
la marcha, sino a que fueran conocidos por Ana y por ellos con antelación, así como las condiciones en que se conseguían o no, con lo que conseguimos dos objetivos importantes: en primer lugar, dar a los premios una función motivadora, además de reforzadora, de la conducta, y en segundo lugar, retirar una importante cantidad de la atención de los padres hacia el problema de su hija, pues ya no necesitaban ni instigarla ni castigarla, ya que al desplazarse la fuente de motivación de ellos mismos al sistema de premios, Ana encontraba sus propios motivos para esforzarse y sabía en todo momento a qué atenerse. Con ello se consiguió, además, estimular su autocontrol y sensación de eficacia personal.

Por último, fue necesario estar muy pendiente de la evolución de las expectativas del padre sobre el tratamiento, ya que en cuanto se produjeron los primeros resultados, cosa que ocurrió muy pronto como es habitual en casos de fobia simple como este, se entusiasmó excesivamente e intentó probar por su cuenta si a su hija se le habían quitado todos los miedos de golpe y a la vez, enfrentándola por ejemplo con un túnel de lavado en marcha. Aprovechamos entonces para reformular positivamente su confianza en el tratamiento, y para aclararle el concepto de generalización del aprendizaje como proceso gradual y desde luego no automático. También se le indicó que los miedos situacionales son muy dependientes del contexto, y que por lo tanto son bastante independientes entre sí. Esta última idea tuvo además la virtud de servir para debilitar todavía más la atribución que hacía a su hija como esencialmente miedosa, al desligar el problema de su identidad y ligarlo a las circunstancias externas. En esto consiste la exteriorización del problema (ver Freeman, Epston y Lobovits 2001): considerar que los niños se enfrentan a un problema, y no que ellos son el problema, lo que permite preservar la fluidez en la formación de su identidad al no definirla como limitada, problemática o inamovible.

\section{Exteriorización del problema}

Precisamente con esta misma intención, pero esta vez enfocado a la interesada, el traba- jo con Ana comenzó animándola a representar y simbolizar su problema mediante el juego de roles con muñecos (ver apartado de evaluación) y mediante el dibujo. De esta forma codificó su experiencia en un formato manejable para ella y susceptible de observación. Al darle una identidad al problema separada de la suya propia, crea un espacio desde el que poder examinar y revisar su relación con dicho problema, y por lo tanto se abre a la posibilidad de controlarlo.

Cuando dibujó lo ocurrido en el ascensor de su colegio, no solo incluyó a todos los personajes importantes (profesora, compañeros, ella misma), sino que también representó el ascensor con todo lujo de detalles. Por ejemplo, pintó dos enormes muelles bajo el ascensor, "para que bote si nos caemos». También incluyó una llamativa palanca en el interior de la cabina, que ella identificaba como la causante de que el ascensor se estropeara. Decía que era «una palanca muy fea» y era obvio que le daba miedo. Entonces la animamos a que la tachara, y ella lo hizo con ganas y también con alivio. En estos dos ejemplos vemos cómo el dibujar lo que causa preocupación al niño puede ayudar a convertir (codificar) una emoción desbordante en una experiencia manejable y con sentido, sobre la que se puede hacer algo para experimentar control y seguridad.

\section{Relajación y Solución Problemas}

Para rebajar la activación producida por los ascensores, y también como estrategia de afrontamiento, se optó por enseñar relajación a Ana. Antes de comenzar el entrenamiento, fue necesario motivar y justificar la técnica. Para esto fueron muy útiles «los cinco fantásticos», que son unos superhéroes con superpoderes que le gustaban mucho. El argumento que captó el interés de Ana por aprender relajación fue que estos personajes conocían un truco secreto para poder enfrentarse al miedo, y que por eso eran capaces de resolver situaciones peligrosas. Terminamos de excitar su curiosidad diciéndole que ese truco nos había sido revelado por alguien secreto y muy especial cuando éramos pequeños, y que a lo mejor otro día podíamos enseñárselo a ella. No fue necesario volver a insistir en el tema, pues a la semana siguiente, 
en mitad de la sesión y mientras jugaba absorta con los muñecos, Ana me preguntó como de pasada si le podía enseñar ya el truco para vencer el miedo.

Entonces, utilizamos una adaptación de la relajación muscular progresiva de Jacobson (1934) en tres fases. Otros sistemas adecuados para relajación de niños se pueden ver en Reiner (1983). La secuencia fue como sigue:

Primero, «tienes que imaginarte que eres un árbol, ponte dura como el tronco de un árbol».

Segundo, «ahora ponte blandita como Coco» (Se recurrió a este personaje infantil porque en la evaluación se averiguó que era agradable y divertido para Ana). risa».

Tercero, "y ahora piensa en algo que te dé

Encontró el procedimiento bastante divertido, y después de practicarlo juntos un par de veces parecía haberlo aprendido bien. Para asegurar el aprendizaje y sobre todo para inducir su uso como estrategia de afrontamiento, la animamos a que escenificara una vez más una historia en la que aparecían sus compañeros de colegio y el ascensor, pero esta vez, junto al personaje que tenía miedo al ascensor, introduje otro que sabía un truco para vencer el miedo. Entonces el terapeuta animó a Ana a que hiciera que este personaje enseñara al miedoso el truco para que pudiera usar tranquilamente el ascensor. Es decir, al principio, representamos la historia tal y como ocurrió. Luego, introdujimos un personaje asegurador, y finalmente el personaje enseñó y aplicó la estrategia de afrontamiento.

Hay que decir que esta estrategia funcionó muy bien. Sin haberle dado ningún tipo de indicación o instrucción explícita para que usara o aplicara la técnica, sino sólo a través de la práctica simbólica, Ana comenzó a utilizar de nuevo los ascensores y a mostrarse visiblemente menos alterada al hacerlo, según relataron sorprendidos sus padres en la siguiente sesión.

También se dedicó tiempo en las sesiones para inventar y escenificar historias de solución de problemas de su entorno cotidiano, aunque no estuvieran directamente relacionadas con la demanda, para reforzar su sensación de control y eficacia personal. Por ejemplo, se planteó una situación en la que una niña había olvidado su estuche en casa y no tenía con qué dibujar, y se animó a Ana a sugerir soluciones a través de la representación de la historia.

\section{Escenificaciones Emotivas}

Como hemos ido viendo, las escenificaciones se utilizaron a lo largo de toda la terapia con diversos objetivos, desde la evaluación continua, hasta la práctica simbólica de habilidades de afrontamiento y solución de problemas. Mencionaremos en este apartado como la empleamos también para desensibilizar una emoción (miedo) ante la situación problemática (ascensores) mediante la exposición repetida en imaginación a dicha situación y mediante la inducción de estados incompatibles (relajación, enfado, risa), todo ello a través de la puesta en escena de historias inventadas.

El procedimiento general ya ha sido ejemplificado anteriormente: primero se representa la historia más o menos como ocurrió. Después, se introducen personajes o modificaciones en la historia con el fin de producir un cambio emocional. Esto suele conseguirse con un personaje asegurador (superhéroe) que enseña y aplica estrategias de afrontamiento, pero también se pueden generar directamente emociones incompatibles, como la ira, aprovechando con imaginación la propia dinámica del juego de roles para enfadar a nuestro pequeño cliente. Por ejemplo, en este caso Ana solía representar la situación amenazante mediante una caja (ascensor) que quería comerse a todos los ositos (alumnos). Entonces se introdujo un dinosaurio que le robaba los ositos a la caja para comérselos antes, y se transformó la historia en un juego competitivo entre la caja y el dinosaurio para ver quién conseguía comerse antes el mayor número de ositos. Mientras la caja (manejada por ella) y el dinosaurio (manejado por el terapeuta) se peleaban, se aprovechaba cualquier ocasión para provocar a la caja y para hacer trampas, con lo que Ana se iba enfadando cada vez más porque no quería perder, y porque el dinosaurio «no sabía jugar». De esta manera, a los pocos minutos se había olvidado por completo del miedo al ascensor. 


\section{Resultados}

La evitación de los ascensores desaparece por completo a partir de la $5^{\mathrm{a}}$ sesión.

Se inicia entonces un seguimiento con registro de 3 semanas. Se mantienen los logros. A partir de la $2^{\mathrm{a}}$ semana de seguimiento, desaparecen también las preocupaciones (operacionalizadas como preguntas reaseguradoras).

Dos meses después, los logros se mantienen y se le da el alta.

En total, el tratamiento consistió en 7 sesiones a lo largo de 3 meses.

\section{Conclusiones}

Una de las primeras tareas que enfrenta un terapeuta al trabajar con padres preocupados es discriminar en qué medida su preocupación es proporcionada y terapéuticamente conveniente. Esta tarea se complica considerablemente si, como en este caso, hay motivos importantes y objetivos para preocuparse. ¿Cómo establecer la frontera entre el cuidado razonable y la sobreprotección cuando un leve golpe o una pequeña herida, tan frecuentes en niños pequeños, pueden ser fatales para la salud de tu hijo?. Una vez aclarada esta distinción para el terapeuta, el siguiente paso importante es ayudar a los padres a manejar y dosificar su preocupación poniendo especial cuidado en no culpabilizarlos. Este es uno de los momentos en terapia donde mejor provecho podemos sacar de nuestro rol de experto si lo administramos con sensibilidad y buen juicio terapéutico, o por el contrario, donde más daño iatrogénico podemos producir si olvidamos que cualquier intervención por nuestra parte, para poder considerarse rigurosa y científica, antes debe ser oportuna y terapéutica.

Es importante acercarse al mundo del niño, pero sintiéndonos cómodos y desde nuestro rol de adulto. El niño nunca nos verá como a un igual (como mucho, seremos «adultos enrollados»), así que no merece la pena intentarlo. Dedicar varias sesiones a dibujar y jugar libremente con el niño no es perder el tiempo, sino que ayuda a establecer un clima de confianza necesario previamente a cualquier intervención, y nos da mucha información de interés sobre el niño y su mundo. No olvidemos que según el modelo evolutivo de Piaget (ver por ejemplo Piaget e Inhelder, 1966/1969), con cuatro años el niño se encuentra en plena etapa pre-operacional y aún no puede separar el pensamiento de la acción. Por esto, cuando esté inmerso en cualquier actividad lúdica reproducirá (representará) lo que le ha impresionado.

Así, conviene vigilar los propios sentimientos del terapeuta de inadecuación o de falta de profesionalidad al tener que salirse de los esquemas preestablecidos, tanto al evaluar como al aplicar técnicas, pues es difícil que en cualquier interacción genuina con el niño este no se manifieste a sí mismo tal cual es, con sus miedos y también con sus habilidades y recursos saludables, sin importar si lo hacemos con procedimientos más o menos pautados, estructurados o formales. De hecho, en este caso se utilizaron las escenificaciones emotivas más como inspiración de base para interactuar con el niño que como programa terapéutico estructurado.

\section{Referencias}

American Psychiatric Association (1994). Manual diagnóstico y estadístico de los trastornos mentales (DSM-IV). Barcelona: Masson.

Caballo, V.E. y Simón, M.A. (2002). Manual de Psicología clínica infantil y del adolescente. Trastornos generales. Madrid: Pirámide.

Freeman, J., Epston, D. y Lobovits, D. (2001). Terapia narrativa para niños: aproximación a los conflictos familiares a través del juego. Barcelona: Paidos.

Greenberg, L.S. y Paivio, S.C. (2000). Trabajar con las emociones en psicoterapia.

Jacobson, E. (1934). You must relax. New York: Whittlesey House.

Méndez, F.X. y Maciá, D. (1988). Escenificaciones emotivas: Una técnica para las fobias infantiles. Análisis y Modificación de Conducta, 14, 323-351.

Piaget, J. e Inhelder, B. (1966/1969). La psicología del niño. Morata, Madrid.

Reiner, K. (1983). El entrenamiento autógeno para niños, adolescentes y padres. TEA Publicaciones de Psicología Aplicada. 